\title{
High spatial resolution magnetic mapping using ultra-high sensitivity scanning SQUID microscopy on a speleothem from the Kingdom of Tonga, southern Pacific
}

\author{
Naoto Fukuyo $1,2,3^{*} \mathbb{C}$, Hirokuni Oda ${ }^{3}$, Yusuke Yokoyama ${ }^{1,2}$, Geoffrey Clark ${ }^{4}$ and Yuhji Yamamoto ${ }^{5}$
}

\begin{abstract}
Speleothems are ideal archives of environmental magnetism and paleomagnetism, since they retain continuous magnetic signals in stable conditions and can be used for reliable radiometric dating using $\mathrm{U}$-series and radiocarbon methods. However, their weak magnetic signals hinder the widespread use of this archive in the field of geoscience. While previous studies successfully reconstructed paleomagnetic signatures and paleoenvironmental changes, the time resolutions presented were insufficient. Recently emerging scanning SQUID microscopy (SSM) in this field can image very weak magnetic fields while maintaining high spatial resolution that could likely overcome this obstacle. In this study, we employed SSM for high spatial resolution magnetic mapping on a stalagmite collected at Anahulu cave in Tongatapu Island, the Kingdom of Tonga. The average measured magnetic field after $5 \mathrm{mT}$ alternating field demagnetization is ca. $0.27 \mathrm{nT}$ with a sensor-to-sample distance of $\sim 200 \mu \mathrm{m}$. A stronger magnetic field (average: ca. $0.62 \mathrm{nT}$ ) was observed above the grayish surface layer compared to that of the white inner part (average: ca. $0.09 \mathrm{nT}$ ) associated with the laminated structures of the speleothem at the submillimeter scale, which scanning resolution of the SSM in this study is comparable to the annual growth rates of the speleothem. The magnetization of the speleothem sample calculated from an inversion of isothermal remanent magnetization (IRM) also suggests that the magnetic mineral content in the surface layer is higher than the inner part. This feature was further investigated by low-temperature magnetometry. Our results show that the main magnetic carriers of the speleothem under study are magnetite and maghemite and it can contain hematite or $\varepsilon-\mathrm{Fe}_{2} \mathrm{O}_{3}$. The first-order reversal curve (FORC) measurements and the decomposition of IRM curves show that this speleothem contains a mixture of magnetic minerals with different coercivities and domain states. The contribution from maghemite to the total magnetization of the grayish surface layer was much higher than the white inner part. Such differences in magnetic mineralogy of the grayish surface layer from that of the inner part suggest that the depositional environment shifted and was likely changed due to the oxidative environment.
\end{abstract}

Keywords: Scanning SQUID microscopy, Paleomagnetism, Environmental magnetism, Speleothem, Magnetite, Maghemite, Hematite, Epsilon iron oxide, South pacific

\footnotetext{
*Correspondence: fukuyo@aori.u-tokyo.ac.jp

1 Atmosphere and Ocean Research Institute, The University of Tokyo,

5-1-5, Kashiwanoha, Kashiwa-shi, Chiba 277-8564, Japan

Full list of author information is available at the end of the article
}

\begin{abstract}
Introduction
Recently, the magnetism of speleothems has been used to reconstruct the geomagnetism and paleoenvironment because they capture the magnetic signals synchronously with the formation of carbonate layers incorporating magnetic minerals (Lascu and Feinberg 2011). Magnetic
\end{abstract}


minerals deposited on speleothems are sourced from flood waters, which flow into caves and/or drip action filtering in overlying soils. The magnetic minerals in speleothems can, therefore, record regional and global environmental changes such as paleofloods, precipitation, and anthropogenic influences as variations in rock magnetic properties (e.g., Lascu and Feinberg 2011; Font et al. 2014; Jaqueto et al. 2016; Chen et al. 2019; Feinberg et al. 2020). For example, Jaqueto et al. (2016) used stalagmites from Brazil and suggested that more negative (positive) values of oxygen and carbon isotopes correspond to lower (higher) values of magnetic mineral content. They suggest that higher isotopic values are interpreted as drier periods, suggesting that vegetation cover controls the magnetic input in the cave (and vice versa). Drier periods (higher $\delta^{18} \mathrm{O}$ and $\delta^{13} \mathrm{C}$ ) are associated with less vegetation cover and more erosion and more transport of Fe-rich sediments into the cave, resulting in higher magnetization. Similarly, Zhu et al. (2017) used magnetic mineral concentration in Chinese speleothems to reconstruct paleo-precipitation. They suggest that a large number of storms and results in extreme rainfall events increase the flux of pedogenic magnetite from soils to the cave, enhancing magnetic mineral quantities. Since the frequency of storms in central China is correlated with El Niño Southern Oscillation (ENSO), they used speleothem magnetic minerals to examine the variability of ENSO over the last $8.6 \mathrm{ka}$. High peaks in IRM of the soft component are coeval with stronger ENSO periods (El Niño) and higher values of carbon isotopes, which is interpreted here as wetter periods.

Despite the advantages mentioned above, the magnetic signals of speleothems are too weak to reconstruct high-resolution paleomagnetic records by conventional magnetometers (Lascu et al. 2016). Thus, previous studies had to sacrifice the temporal resolution that speleothems could potentially offer. However, scanning SQUID microscopy (SSM) can image very weak magnetic fields above natural geological samples with a high spatial resolution of $\sim 100 \mu \mathrm{m}$ (e.g., Lima and Weiss 2016; Oda et al. 2016), which could solve the problem of weak magnetism associated with paleo- and environmental magnetic studies using speleothems. To date, only a few preliminary relevant studies have been reported using SSM for speleothems (e.g., Myre et al. 2019; Feinberg et al. 2020).

Here, we report for the first time a high-resolution and high-sensitivity magnetic mapping using an SSM for a speleothem collected from the South Pacific together with dedicated rock magnetic measurements to unveil the magnetic minerals and their origins. The speleothem sample was collected from Tongatapu Island, the Kingdom of Tonga, where is an archaeologically important region as a base for human migration to East
Polynesia (e.g., Clark et al. 2015). However, few quantitative paleoenvironmental studies using Earth-scientific methods have been reported (e.g., Roy 1997; Fukuyo et al. 2020). The speleothem magnetism is expected to contribute to the studies of archaeology, such as the Polynesian expansion over the South Pacific islands during the Holocene, by providing information on magnetic minerals reflecting the change in depositional environment such as oxidation states, which might originate from human activity and/or environment.

\section{Sample and methods}

A stalagmite sample, AAC, was retrieved from the Anahulu cave in Tongatapu island $\left(21^{\circ} 12^{\prime} 26^{\prime \prime} \mathrm{S}, 175^{\circ} 05^{\prime}\right.$ $59^{\prime \prime}$ W, Additional file 1: Figure S1, Worthy et al. 1991). It consists mostly of the white part, with gray layers only in the surface portion of the stalagmite (ca. $1 \mathrm{~mm}$ depth). Moreover, the thin reddish-brown layer exists at the boundary between the gray and white part (Fig. 1a). Stalagmite AAC was first cut perpendicular to its growth direction. For SSM measurements, the topmost part of the speleothem was sliced and polished to a thickness of approximately $200 \mu \mathrm{m}$ (Fig. 1b, c). For rock magnetic measurements using a magnetic property measurement system (MPMS) and an alternating gradient force magnetometer (AGM), a small quantity of material was collected from the gray (AAC-B3) and white (inner part, AAC-W3) sections of the speleothem using a ceramic scalpel, and diamond wire saw.

The reddish-brown layer, however, could not be separated from the gray layer and white part because of its thinness $(<0.1 \mathrm{~mm})$ and proximity to the gray layer (ca. $0.7 \mathrm{~mm}$ ). Thus, a sample of a mixture of gray layers and white part, including the reddish-brown layer (AAC-M), was also collected for MPMS and AGM measurements. For radiocarbon measurements, approximately $5 \mathrm{mg}$ of calcites were drilled from the stalagmite growth layers (Fig. 1b). The powdered sample was graphitized using the method described by Yamane et al. (2019) and then measured by a single-stage accelerator mass spectrometry at the Atmosphere and Ocean Research Institute, The University of Tokyo (Yokoyama et al. 2019). The ${ }^{14} \mathrm{C}$ ages were calibrated to calendar ages using OxCal 4.4 (Ramsey 2009a) with SHCal20 (Hogg et al. 2020). Moreover, a portion of the dating results was constrained using a P_sequence model (Ramsey 2008; Ramsey and Lee 2013) and a general temporal outlier model (Ramsey 2009b).

The SSM measurements were conducted using the SSM at the Geological Survey of Japan (GSJ), National Institute of Advanced Industrial Science and Technology (AIST) (Kawai et al. 2016; Oda et al. 2016). All measurements were performed with constant parameters described below except sensor-to-sample distance: 


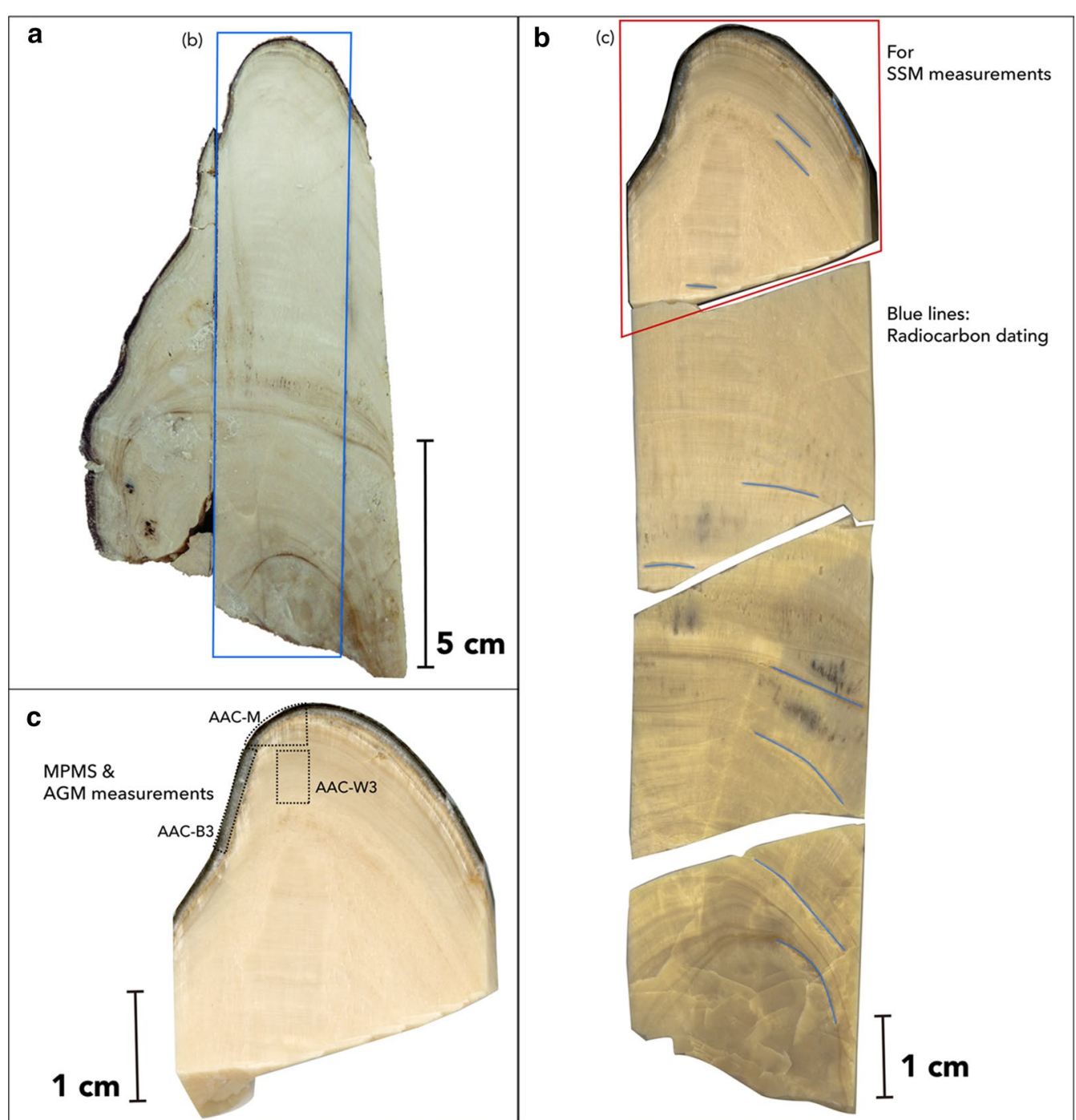

Fig. 1 a Photo of a half-split sample of a speleothem; $\mathbf{b}$ SSM measurements and ${ }^{14} \mathrm{C}$ dating; and $\mathbf{c}$ MPMS and AGM measurements

scanning steps of $\mathrm{x}$ and $\mathrm{y}$ axes were $100 \mu \mathrm{m}$; speeds of $\mathrm{x}$ and $\mathrm{y}$ axes were $150 \mathrm{~mm} / \mathrm{min}$; delay time before data acquisition was $0.05 \mathrm{~s}$; scanning mode was one-way scanning in the direction of the y-axis. The sensor-to-sample distance was set to be approximately $250-350 \mu \mathrm{m}$ depending on measurement runs. First, natural remanent magnetization (NRM) at alternating field demagnetization (AFD) steps of $0,5,10$, and $30 \mathrm{mT}$, which was done using an $\mathrm{AF}$ demagnetizer equipped with a two-axis tumbler (DEM-95C; Natsuhara Giken Co. Ltd.), was analyzed. At the same time, we conducted measurements of three components of magnetization with a superconducting rock magnetometer (SRM) at GSJ-Lab, AIST on the thin section after SSM measurement at each demagnetization step (Additional file 2: Figure S2a and S2b).
Subsequently, isothermal remanent magnetization (IRM) was imparted to the thin section by a DC field of $1.4 \mathrm{~T}$ using an electromagnet and was subsequently analyzed. Distributions of magnetic moments were calculated from the magnetic field data of IRM by assuming equally spaced magnetic dipoles on $200 \mu \mathrm{m}$ grids, with upward magnetic moments perpendicular to the thin section using the inversion algorithm of Weiss et al. (2007).

Optical images were taken separately with an optical scanner (spatial resolution of $4 \mu \mathrm{m}$ ), overlaid with the magnetic image by marking two artificial magnetic dipoles for reference Oda et al. (2016). The SSM data were processed according to the procedure described in Oda et al. (2016). Additionally, the signal of a reference sensor was subtracted from that of the main sensor 
before processing after the introduction of the sensor for the removal of environmental noise (Oda et al. 2020). Though the standard procedure was adjusted for drift correction (Weiss et al. 2007), weak magnetization and contamination of magnetic dust particle contamination gave unsatisfactory results. Thus, we developed an improved method as follows: the median of magnetic data in each margin of a measurement line is extracted, and the average is calculated using the data that only values under within a predefined threshold value from the median. Then the average was used as a background value for drift correction. By choosing the lengths of margins and the threshold value properly, the magnetic maps were improved, especially for scanned lines with serious contamination in the background area. Finally, a median filter $(3 \times 3$ points) is performed to remove spike noise (Noguchi et al. 2017).

The low-temperature rock magnetic measurements were conducted using an MPMS (MPMS-XL5, Quantum Design) at the Center for Advanced Marine Core Research (CMCR), Kochi University, for analyses mostly relevant to temperature cycles. The sequences of measurement cycles are listed below:

1. Zero-field (ZF) cycling curve: imparting saturation isothermal remanent magnetization (SIRM) by a magnetic field of $5 \mathrm{~T}$ at room temperature (300 K); measuring a remanence continuously while cooling from 300 to $10 \mathrm{~K}$ and warming back to $300 \mathrm{~K}$ in zero field.

2. Field cooling (FC) curve: cooling from 300 to $10 \mathrm{~K}$ in a magnetic field of $5 \mathrm{~T}$; measuring a remanence in zero field during warming from 10 to $300 \mathrm{~K}$.

3. Zero-field cooling (ZFC) curve: cooling from 300 to $10 \mathrm{~K}$ in zero field; imparting SIRM in a field of $5 \mathrm{~T}$ at $10 \mathrm{~K}$; measuring a remanence in zero field during warming from 10 to $300 \mathrm{~K}$.

4. $400 \mathrm{~K}$ thermoremanent magnetization (TRM) and ZF-cycling: imparting TRM by heating to $400 \mathrm{~K}$ and cooling to $300 \mathrm{~K}$ in a magnetic field of $300 \mathrm{mT}$ (Guyodo et al. 2006; Lascu and Feinberg 2011); measuring a remanence with the same protocol of ZF-cycling.

5. $400 \mathrm{~K}$ thermal demagnetization (ThD) and ZFcycling: ThD by heating to $400 \mathrm{~K}$ and cooling to $300 \mathrm{~K}$ in zero field; imparting IRM with a magnetic field of $300 \mathrm{mT}$ at $300 \mathrm{~K}$; measuring a remanence with the same protocol of ZF-cycling.

Note that a difference between the two measurements of 4 and 5 was used to diagnose the presence of goethite (Lascu and Feinberg 2011). Moreover, IRM acquisition curves were obtained at 60 steps on a logarithmic scale up to $5 \mathrm{~T}$ at room temperature before heating to $400 \mathrm{~K}$ for experiments 4 and 5. IRM acquisition results were decomposed by Max UnMix software (Maxbauer et al. 2016).
The other rock magnetic measurements were conducted using an AGM (PMC MicroMag 2900 AGM; Lake Shore Cryotronics, Inc.) at GSJ, AIST, for hysteresis and first-order reversal curve (FORC) analyses. To reduce the noise, multiple FORC measurements were stacked. Hysteresis data were processed with the HystLab (Paterson et al. 2018), and FORC measurement data were analyzed by the FORCinel (Harrison and Feinberg 2008).

\section{Results \\ Radiocarbon dating}

We obtained nine radiocarbon dates, which were calibrated using OxCal 4.4 with a P_Sequence agedepth model (Additional file 3: Figure S3, Additional file 4: Table S1). The single calibrated ages ranged from $4370 \pm 60 \mathrm{cal}$ years BP at $0.8 \mathrm{~mm}$ from the top to $27,100 \pm 100 \mathrm{cal}$ years BP at $109.3 \mathrm{~mm}$ from the top along the centerline of the growth axis. A significant age-gap of more than 20,000-years occurs around $1 \mathrm{~mm}$ from the top, coinciding with a boundary of gray and white part, which suggests the presence of a hiatus in growth. Moreover, an age-gap of 1000 years between AAC9 and AAC10 may suggest the existence of another hiatus (Additional file 3: Figure S3, Additional file 4: Table S1). The modeled ages, which were calculated by applying the $\mathrm{P}$ _Sequence model for $\mathrm{AAC} 2-\mathrm{AAC}$, ranged from $25,950 \pm 50$ cal years BP at $7.6 \mathrm{~mm}$ from the top to $26,000 \pm 100 \mathrm{cal}$ years $\mathrm{BP}$ at $97.0 \mathrm{~mm}$ (see Additional file 4: Table S1). The ages showed good agreement with modeled ages, apart from AAC2 at $7.6 \mathrm{~mm}$ depth. No age reversals were observed along the speleothem growth direction. Assuming that a layer of stalagmite corresponds to 1 year, the number of layers existed between the nine dated layers is consistent with the dates obtained from radiocarbon dating except for the gap between AAC1 and AAC2 (Additional file 4: Table S1). Dating results clearly indicate that the gray layers and white part are formed, respectively, during the Holocene and the last glacial (see Additional file 5).

$\delta^{13} \mathrm{C}$ values were also measured by AMS (Additional file 4: Table S1). AMS $\delta^{13} \mathrm{C}$ values are less precise than IRMS $\delta^{13} \mathrm{C}$, because AMS $\delta^{13} \mathrm{C}$ can have isotopic fractionation occurring in the sputter ion source or other parts of the AMS instrument. However, AMS $\delta^{13} \mathrm{C}$ values, instead of IRMS $\delta^{13} \mathrm{C}$, were preliminary used for discussion on the sources of carbon in this study. $\delta^{13} \mathrm{C}$ of AAC1 (0.8 $\mathrm{mm}$ from the top) was ca. $-6.03 \%$, while the average $\delta^{13} \mathrm{C}$ from AAC2-10 were ca. $-12.03 \%$. There is a significantly large gap between $\mathrm{AAC} 1$ and $\mathrm{AAC} 2$ by taking into account the measurement precision of $\delta^{13} \mathrm{C}$ $(<0.15 \%$ ) . 


\section{SSM measurements}

Optical (Fig. 2a) and magnetic images (Fig. 2b) were first taken for NRM before AF demagnetization, and an overlay image was produced (Fig. 2c) for SSM measurements. The grayish surface layer that was observed in the optical image shows positive magnetic anomalies of approximately $0.15 \mathrm{nT}$ (standard deviation: $0.48 \mathrm{nT}$ ) on average, whereas weak negative anomalies (average $\sim-0.58 \mathrm{nT}$, standard deviation: $0.26 \mathrm{nT}$ ) were recognized in the white part (Fig. 2d). In contrast, there are no detectable features in the magnetic image corresponding to the reddish-brown layer.

After demagnetization at $5 \mathrm{mT}$, a magnetic image of NRM for the white inner part shows weak positive anomalies of ca. $0.1 \mathrm{nT}$ (Additional file 6: Figures S4b and S4c), which is different from the values obtained from NRM. Furthermore, a weak magnetic feature corresponding to the reddish-brown layer could be observed. Even after demagnetization at $10 \mathrm{mT}$ and $30 \mathrm{mT}$, the white inner part shows weak positive anomalies (Additional file 6: Figures S4e, S4f, S4h, and S4i). The cross-sectional diagrams along the growth axis of the speleothem show the change of magnetic field values through AFD (Fig. 3b, d, $\mathrm{f}$, and $\mathrm{h}$ ). Moreover, measurements with a superconducting rock magnetometer (SRM) on the thin section suggest that viscous magnetic overprints could be removed by AFD at 5-10 $\mathrm{mT}$ and AF demagnetization at $30 \mathrm{mT}$ would remove $~ 80 \%$ of NRM (see Additional file 5: Figure S2).

Magnetic images of IRM indicate that magnetic field values above the gray layer and the reddish-brown layer are much higher than those above the white part (Fig. 2e, $\mathrm{f}$, and g). Furthermore, magnetic moment values above the gray layer are higher than those above the white part (Fig. 2h, i). The peak moment of the grayish layer $\left(x=11.5 \mathrm{~mm}\right.$ in Fig. $2 \mathrm{i}$ ) is marked as $2.03 \times 10^{-12} \mathrm{Am}^{2}$, whereas the average of the white part is $4.98 \times 10^{-14} \mathrm{Am}^{2}$ (the range is from $15.1 \mathrm{~mm}$ to $42.5 \mathrm{~mm}$ in Fig. 2i).

\section{Magnetic mineralogy with low-temperature magnetometry}

Results from low-temperature magnetometry experiments for samples AAC-B3, AAC-W3, and AAC-M are shown in Fig. 4. In general, inflection points around

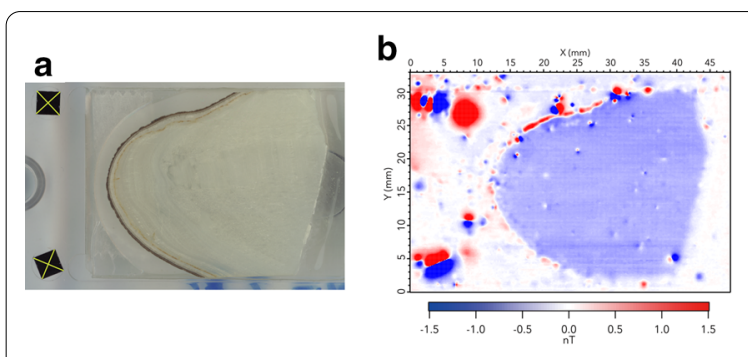

e
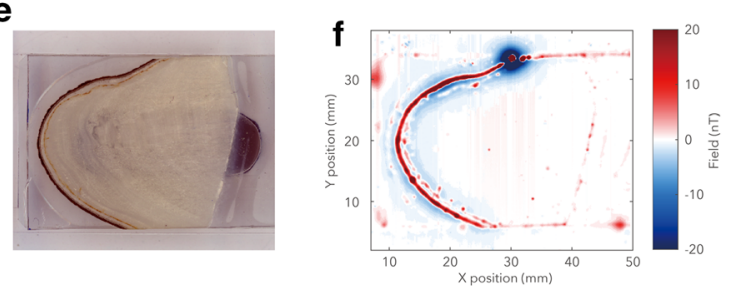

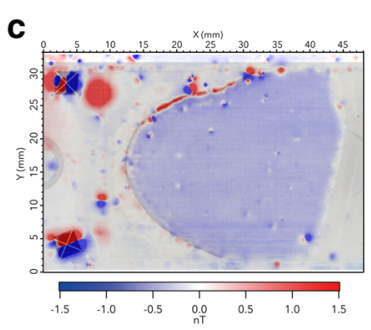

g

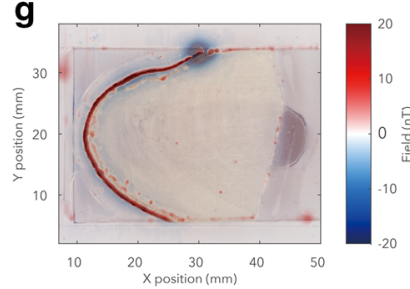

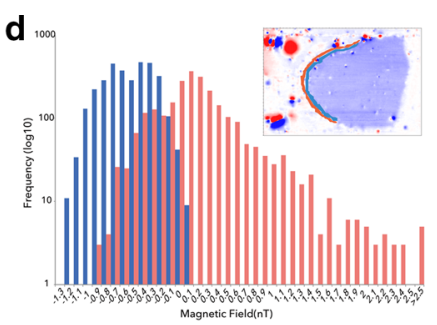

h
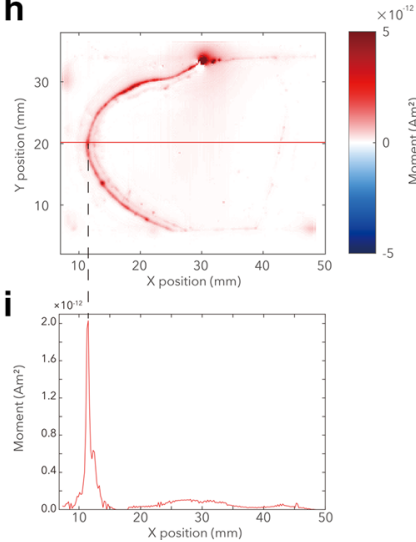

Fig. 2 Optical and magnetic images of NRM and IRM and their analyses. a Optical image, $\mathbf{b}$ magnetic image of NRM, and $\mathbf{c}$ optical image overlaid on the magnetic image of NRM. $\mathbf{d}$ Distribution of magnetic field within the highly magnetic layer next to the surface and the layer slightly inside with less magnetic feature. Each dataset was selected according to the region shown in the inset figure on the upper-right; i.e., red and blue correspond to the magnetic and less magnetic areas, respectively. e Optical image (contrast has been changed from a for better visibility of the colored surface layers), $\mathbf{f}$ magnetic image of IRM (1.4 T), and $\mathbf{g}$ optical image overlaid on a magnetic image of IRM (1.4 T). $\mathbf{h}$ Magnetic moment distribution of IRM image calculated on $0.2 \mathrm{~mm} \times 0.2 \mathrm{~mm}$ grid points from the magnetic field in $\mathbf{f}$. Magnetic moment distributions were calculated, according to Weiss et al. (2007). $\mathbf{i}$ Line profile along a horizontal line in $\mathbf{h}$ at $20.1 \mathrm{~mm}$ of $Y$ position. The range of gray shade is the same as the range of a light green square in $\mathbf{h}$ 


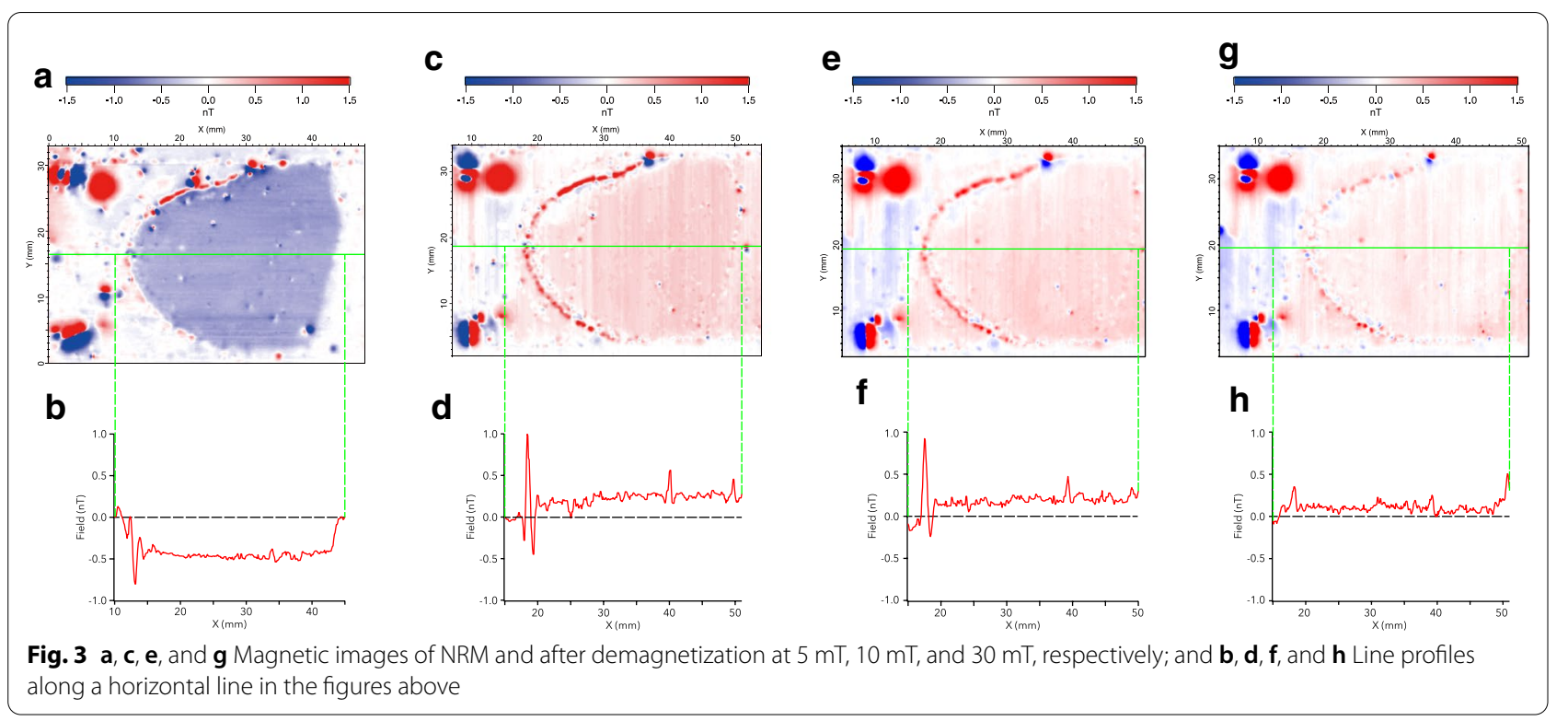

$100 \mathrm{~K}$ could be recognized for the cooling curves of ZF-cycling (Fig. 4a-c). The inflections for AAC-B3 and AAC-M broadened and slightly shifted to a lower temperature compared to AAC-W3. In the warming curve of ZF-cycling and FC/ZFC curves of AAC-W3 (Fig. 4b and Additional file 7: Figure S5), inflection points around $100 \mathrm{~K}$ could be observed, while in the corresponding diagrams of AAC-B3 and AAC-M (Fig. 4a-c, and Additional file 7: Figure S5), such inflections were not observed.

It is noteworthy that the cooling curve of TRM for AAC-M shows an inflection point around $200 \mathrm{~K}$ (Fig. 4f), which could be revealed as a sharp drop in the difference between the cooling curves of TRM and ThD for AAC-M (Fig. 4i). In addition, the difference between the ZFcycling curves of TRM and ThD for AAC-B3 and AACW3 cannot be distinguished from zero at the levels of three standard deviations at $300 \mathrm{~K}$ (within the margins of error) (Fig. 4g, h).

\section{Hysteresis and domain state diagnosis using FORC}

Hysteresis loops are analyzed for the samples collected from the gray surface layer (AAC-B3), where saturation magnetization (Ms: $1.14 \times 10^{-3} \mathrm{Am}^{2} / \mathrm{kg}$ ) was about two times higher than that of the white inner part (AACW3 $6.32 \times 10^{-4} \mathrm{Am}^{2} / \mathrm{kg}$ ). This is consistent with the SSM measurements, and which suggests that higher concentrations of magnetic minerals are contained in the grayish layer than in the white part. In addition, the mixture of gray layers and white part (AAC-M) has a similar value of $\mathrm{Ms}\left(7.51 \times 10^{-4} \mathrm{Am}^{2} / \mathrm{kg}\right)$ to that of
AAC-W3. Meanwhile, coercivities (Hc) of all samples indicated almost the same values (AAC-B3: $7.6 \mathrm{mT}$; AAC-W3: $7.9 \mathrm{mT}$; and AAC-M: $8.2 \mathrm{mT}$ ).

FORC diagrams of AAC-B3 (Fig. 5d) and AAC-M3 (Fig. 5f) were similar and showed a small peak around the $\mathrm{Bc}$ axis and a spreading of the FORC distributions along the $\mathrm{Bu}$ axis with a sharp peak at around zero. Both diagrams also showed a diagonal distribution extending to the lower-right between the $\mathrm{Bu}$ and $\mathrm{Bc}$ axis. Though the FORC diagram of AAC-W3 (Fig. 5e) was noisier than the others, similar patterns could be observed.

\section{Identification of coercivity components using IRM acquisition curves}

Analytical results of the IRM acquisition curves by the Max UnMix software (Maxbauer et al. 2016) suggest that the grayish layer (AAC-B3) and the mixed layer (AAC-M) consist of three coercivity components (Fig. 4j, 1), whereas the white part (AAC-W3) consists of two components (Fig. 4k). Each layer has two similar main components: the very-low-coercivity component (Comp-1) and the low-coercivity component (Comp-2). Comp-1 is characterized by a coercive field (Bh) of $4.7-$ $5.9 \mathrm{mT}$ and a dispersion parameter (DP) of 0.34-0.38. A Bh of Comp-2 is 19.5-21.5 mT with a DP of 0.31-0.37. The intermediate-coercivity component (Comp-3) is observed in AAC-B3 and AAC-M but not in AAC-W3. Comp-3 is characterized by a $\mathrm{Bh}$ of $36.5-38.5 \mathrm{mT}$ and a DP of 0.24-0.29. 

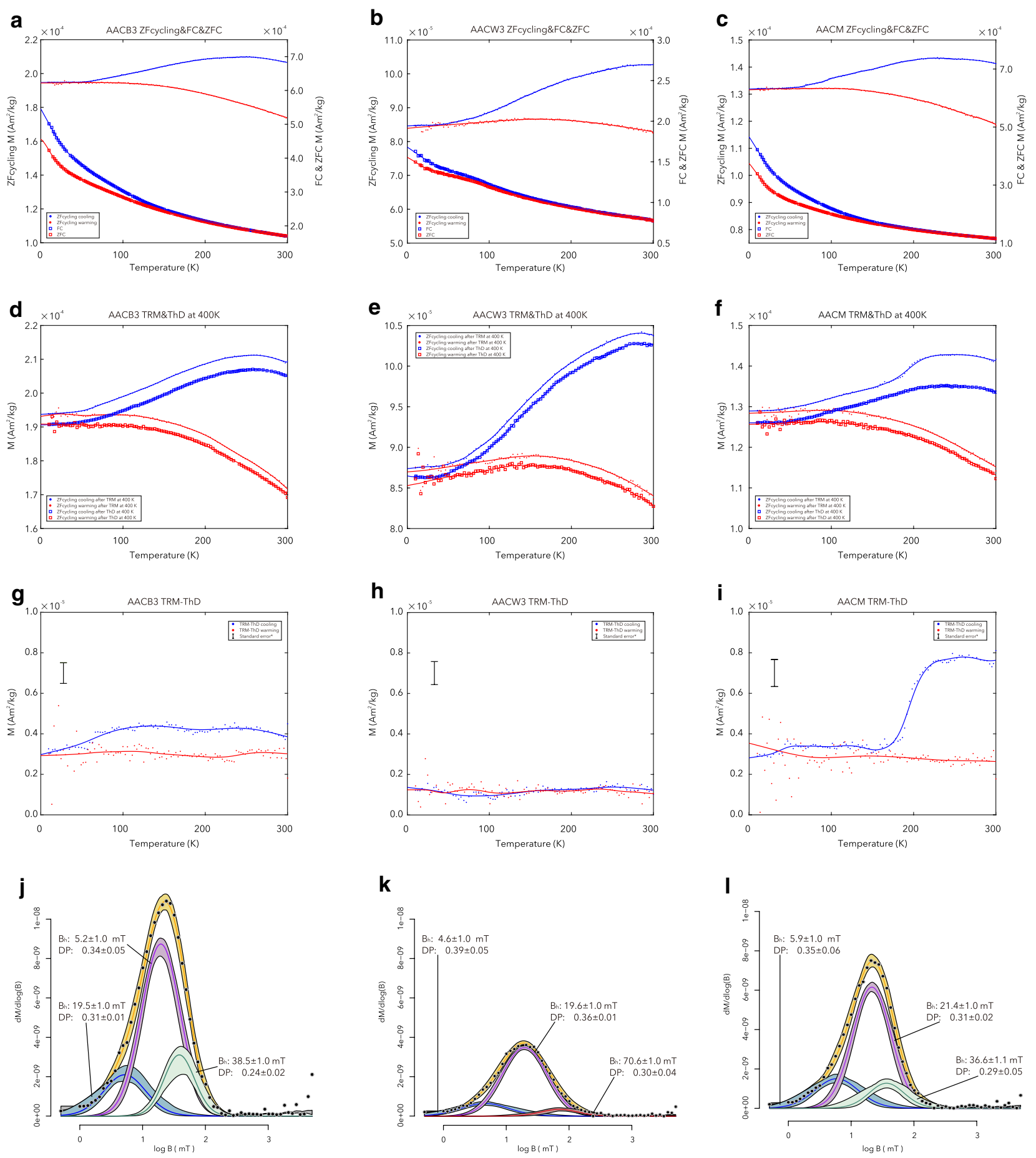

Fig. 4 ZF-cycling curves and FC/ZFC curves of a AAC-B3 (the gray layer), b AAC-W3 (the white inner part), and c AAC-M (the mixture of gray layers and white part including reddish-brown layer); ZF-cycling curves after TRM at $400 \mathrm{~K}$ and ZF-cycling curves after ThD at $400 \mathrm{~K}$ of $\mathbf{d}$ AAC-B3, e AAC-W3, and $\mathbf{f} A A C-M$; the difference between ZF-cycling curves after TRM and ZF-cycling curves after ThD of $\mathbf{g} A A C-B 3, \mathbf{h}$ AAC-W3, and i AAC-M; unmixing models of IRM acquisition curves of $\mathbf{j} A A C-B 3, \mathbf{k}$ AAC-W3, I AAC-M. $B_{h}$ and DP are the mean coercivity and the dispersion parameter (given by one standard deviation) of an individual grain population assuming a Gaussian distribution in log space, respectively 

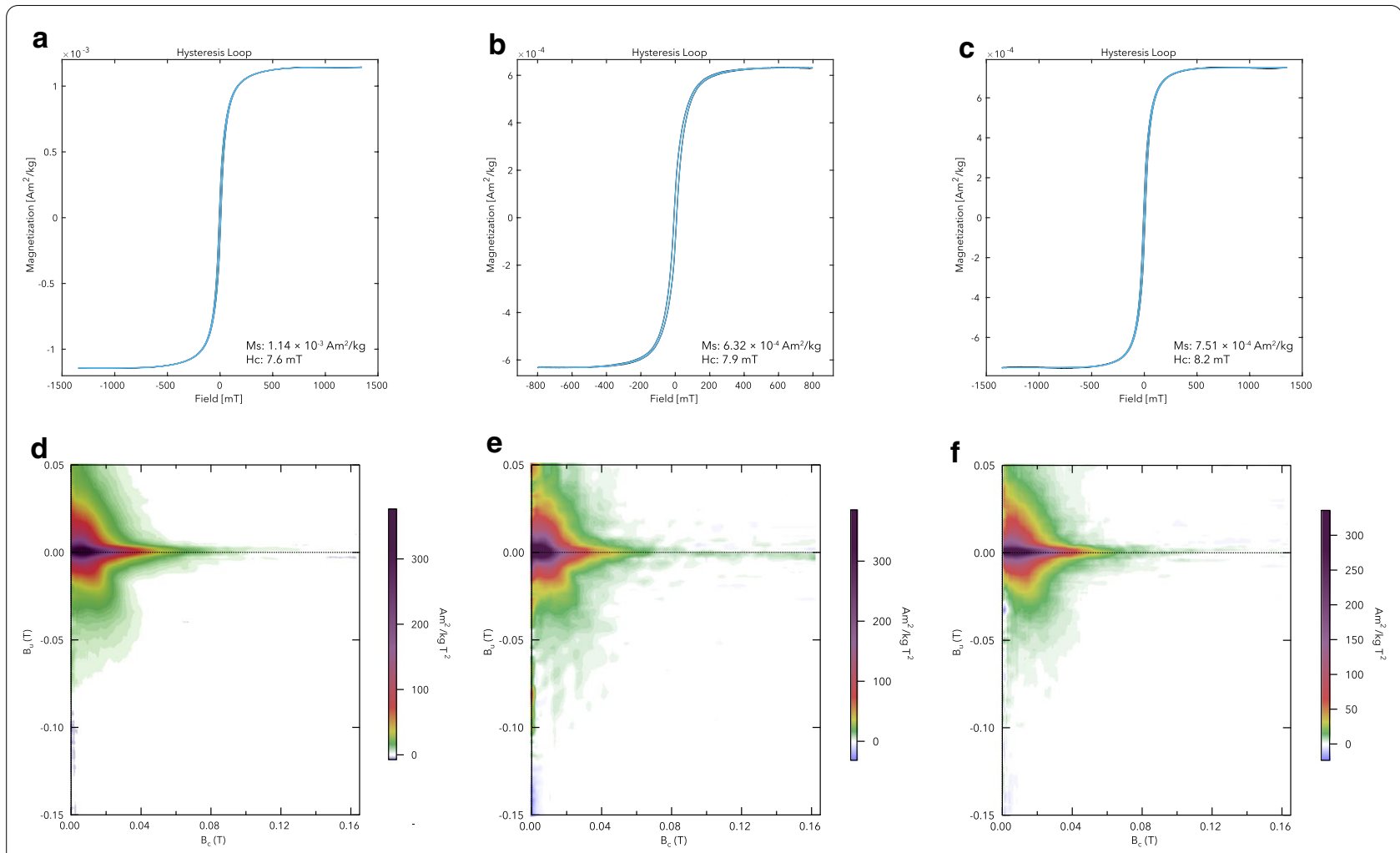

Fig. 5 Results of measurements with AGM for samples from the grayish section (AAC-B3), the white section (AAC-W3), and the mixture of gray layers and white part (AAC-M). Hysteresis loops of a AAC-B3, b AAC-W3, and $\mathbf{c} A A C-M$, and FORC diagrams of $\mathbf{d} A A C-B 3$, e AAC-W3, and $\mathbf{f} A A C-M$

\section{Discussion}

\section{Sensitivity, reliability, and implications of SSM} measurements

Although the magnetic field produced by the studied speleothem thin section was quite weak ( $0.1 \mathrm{nT}$ or less), our SSM measurements successfully provided information on distributions of variable magnetization at a resolution of $\sim 100 \mu \mathrm{m}$. The new procedure of drift corrections applied in this study is based on taking the average along with line scan measurements between predefined threshold values (excluding local magnetic anomalies produced by contaminated dust particles, etc.) away from the median value in the marginal band area used for drift correction.

SSM magnetic images of NRM indicated that NRM before AF demagnetization (Fig. 3a, b) is dominated by negative anomalies (magnetized in the downward direction relative to the surface of the thin section), which is the opposite polarity to the other SSM magnetic images (i.e., $5 \mathrm{mT}, 10 \mathrm{mT}$, and 30mT; Fig. 3c-h). This suggests that secondary magnetization was acquired after speleothem formation, which was removed by AF demagnetization at $5 \mathrm{mT}$. This is confirmed by the magnetization measurements on the thin section with the SRM (Additional file 5: Figure S2). The results of the SSM magnetic imaging and SRM measurements suggest that the averaged coercivity of the speleothem is $\sim 10-20 \mathrm{mT}$, and the NRM can be reduced to $\sim 20 \%$ by AFD at $30 \mathrm{mT}$. Meanwhile, the previous studies on speleothems from Canada, the UK, and Mexico (Latham et al. 1979, 1986, 1987) and from Japan (Morinaga et al. 1989) reported the removal of viscous remanent magnetization (VRM) by AF demagnetization using peak fields of 5-10 mT. Speleothems from China showed the removal of VRM by AF peak field of $30 \mathrm{mT}$ (Openshaw et al. 1997). Thus, the secondary magnetization could be adequately removed in the speleothem by AF demagnetization.

SSM magnetic images of IRM suggest that the concentration of magnetic minerals is higher in the gray layer than in the white part (Fig. 2h, i). We estimated magnetic concentration for the grayish layer and the white part based on the estimated magnetic moments (Fig. 2i). As mentioned in the methods section, the thickness of the samples is $200 \mu \mathrm{m}$, and we calculated a magnetic moment on a $200 \mu \mathrm{m}$ grid. Thus, the saturation magnetization of the grayish layer is $2.54 \times 10^{-1} \mathrm{~A} / \mathrm{m}$, and that of the white part is $6.23 \times 10^{-3} \mathrm{~A} / \mathrm{m}$. As described below, the main magnetic remanence carriers in the speleothem studied could be magnetite. Assuming that all magnetic remanence carriers in the speleothem are single-domain 
magnetite (Ms: $446 \mathrm{kA} / \mathrm{m}$; $\mathrm{Mrs} / \mathrm{Ms}=0.5$ ), we can estimate that the magnetic concentrations per volume in the speleothem of the gray layers and white part as $1.14 \times 10^{-6}$ and $2.79 \times 10^{-8}$, respectively.

The above-described experiments demonstrated that SSM is capable of imaging very weak magnetic field differences induced from differences in laminated structures of a speleothem at a resolution of $\sim 100 \mu \mathrm{m}$.

\section{Magnetic minerals in the speleothem}

Magnetic mapping of the speleothem from the stalagmite of Anahulu cave with the submillimeter scale resolution with SSM (Fig. 2a-c) clearly showed a difference in the magnetization distributions among the grayish surface layer, the white inner part, and the reddish-brown layer (Fig. 2e-f). A series of rock magnetic results suggest that the main magnetic remanence carriers in the speleothem studied are magnetite and maghemite, and the minor magnetic remanence carrier is hematite (or $\varepsilon-\mathrm{Fe}_{2} \mathrm{O}_{3}$; see discussion below). Similar results have been obtained in other stalagmites (e.g., Strauss et al. 2013; Font et al. 2014; Jaqueto et al. 2016).

The cooling curves of ZF-cycling for AAC-B3 and W3, and the warming curve of ZF-cycling and $\mathrm{FC} / \mathrm{ZFC}$ curves for AAC-W3 show the characteristic inflection points at $100 \mathrm{~K}$ (Fig. 4a, b, d, and e), which can be attributed to the Verwey transition ( $125 \mathrm{~K}$ for stoichiometric magnetite, e.g., Jackson and Moskowitz 2021), a diagnostic feature of magnetite. The relatively sharp inflection observed for the white inner part (AAC-W3) suggests that their main magnetic carrier is relatively stoichiometric magnetite. In contrast, the vague shift to lower temperatures or absence of the Verwey transition for the grayish surface layers (AAC-B) is considered as the result of highly oxidized (deviation from stoichiometry) magnetite (e.g., Jackson and Moskowitz 2021). The difference between the ZF-cycling curves of TRM and ThD for AAC-B3 and $\mathrm{M}$ was not distinguished from zero at $300 \mathrm{~K}$ (Fig. $4 \mathrm{~g}, \mathrm{~h}$ ). These features can indicate the absence of goethite (Lascu and Feinberg 2011).

On the other hand, the inflection point at ca. $200 \mathrm{~K}$ in the TRM curve for AAC-M seems to be related to a Morin transition, which can suggest the presence of hematite (Fig. 4f, i). In general, Morin transition occurs at ca. $260 \mathrm{~K}$, but it can be shifted toward lower temperatures for impure hematite (e.g., de Boer et al. 2001; Liu et al. 2010). Thus, the inflection point at ca. $200 \mathrm{~K}$ in TRM, which can be observed only in AAC-M, may suggest that hematite exists in the reddish-brown layer. Meanwhile, the inflection point can alternatively be explained by the presence of $\varepsilon-\mathrm{Fe}_{2} \mathrm{O}_{3}$. The magnetic property of $\varepsilon-\mathrm{Fe}_{2} \mathrm{O}_{3}$ corresponds to a high coercive field and low unblocking temperature (e.g., Tuček et al. 2010; López-Sánchez et al.
2017; Kosterov et al. 2020b). Furthermore, the occurrence of $\varepsilon-\mathrm{Fe}_{2} \mathrm{O}_{3}$ is related to the anthropogenic fire (e.g., López-Sánchez et al. 2017; Kosterov et al. 2020a) or the vegetation change (McClean et al. 2001). This is consistent with the environmental magnetic implication we discussed below.

If we take the IRM decomposition results into account, it suggests that the main magnetic components of the speleothem are magnetite. Comp-1 (Bh: 4.7-5.9 mT; DP: $0.35-0.38$ ) can be identified as a low-coercivity multidomain (MD) magnetite (e.g., Maxbauer et al. 2017; He and Pan 2020). Comp-2 (Bh:19.5-21.4 mT; DP: 0.31$0.37)$ represents a mixture of magnetite and maghemite (e.g., Abrajevitch and Kodama 2011; Font et al. 2014; Jaqueto et al. 2016). Comp-3 (Bh: 36.5-38.5 mT; DP: 0.24-0.29), which is observed in AAC-B3 and AAC-M, not in AAC-W3, are highly consistent with observations of oxidized pedogenic magnetite from previous work (e.g., Egli 2004; Maxbauer et al. 2017), which is considered as mainly single domain particles.

Thus, the assemblage of magnetic minerals in the grayish surface layer comprises a mixture of MD magnetite, PSD magnetite/maghemite and SD magnetite/maghemite. In contrast, the assemblage of magnetic minerals in the white inner part is dominated by MD magnetite and PSD magnetite/maghemite without pedogenic SD magnetite/maghemite. We suggest that the environmental condition that supplied magnetic minerals included in the surface grayish layer is different from that of the inner white part. Furthermore, hematite (or $\varepsilon-\mathrm{Fe}_{2} \mathrm{O}_{3}$ ) could be observed only in the reddish-brown layer, which was also recognized as a thin detectable feature in the SSM image of NRM after demagnetization and IRM acquisition.

FORC diagrams have three features: (1) the small peak around the Bc axis; (2) the spreading of the FORC distributions along the $\mathrm{Bu}$ axis with a sharp peak at around zero; (3) and a diagonal distribution extending to the lower-right between the $\mathrm{Bu}$ and $\mathrm{Bc}$ axis. These features can suggest the presence of pseudo-single domain (PSD) magnetite (Lascu et al. 2018). Alternatively, these features may suggest the mixture of single-domain (SD) and multi-domain (MD) particles, where SD particles are characterized as the existence of central-ridges around the $\mathrm{Bu}$ axis (Roberts et al. 2014) and multi-domain (MD) particles are represented as horizontal spreads (Lascu et al. 2018), respectively. Although FORC diagrams in this study have some noise even after stacking, we could tentatively interpret the FORC diagrams in combination with IRM component analyses that the gray part is dominantly composed of SD, PSD, and MD particles, whereas the white part is dominantly composed of PSD and MD particles. Recently, Ahmed and Maher (2018) showed that magnetite formation in Chinese paleosol occurs in 
well-drained, generally oxidizing soils. They also suggested that maghemite was present as an oxidized shell around the magnetite, where coatings of clay minerals are preventing the transport of oxygen to their surface. Their results have profound implications on our future studies in connecting to climate change and human activities.

\section{Environmental implication}

Results obtained from this study demonstrate that different magnetic properties can be detected clearly between the two layers using SSM. Concentrations of magnetic minerals are higher in the gray layer, whereas much smaller in the white part. The type of magnetic minerals contained in the two layers also can be distinguished, and a hiatus in growth appears to exist between the two layers.

According to Lascu and Feinberg (2011), the deposition rate of detrital magnetic minerals onto the speleothem surface is controlled by precipitation, flood frequency, and the surface soil above the cave. The depositional mechanism of gray layers and white part could potentially be attributed to changes in ambient environments. Previous studies showed that frequent events such as extreme climate changes, including floods and/or tsunamis, could have been recorded as distinct, several colored layers (e.g., Denniston and Luetscher 2017; Feinberg et al. 2020).

The distinct gray color on the white calcium carbonate speleothem may have been deposited with influence from non-carbonate minerals. The surface geology of Tongatapu island consists mainly of limestones overlain by two soil layers of andesitic volcanic ash, which are estimated to be aged at 20,000 and 5000 years from active volcanoes in the north, such as Tofua and Kao island (e.g., Cowie et al. 1991; Spennemann 1997; Manu et al. 2014). Soils of Ha' apai, Kingdom of Tonga, which are correlated with the soils of Tongatapu, are high in iron oxide minerals by weight (Childs and Wilson 1983). Furthermore, typical soils containing volcanic ash is acidic; thus, magnetite in the soil could oxidize to maghemite (Taylor and Schwertmann 1974). Therefore, the gray layers may have been formed due to volcanic eruptions 5000 years ago that occurred in the northern islands.

The other possible scenario would be the potential influence of human activities. The first human settlement on Tongatapu ranges from 2863 to 2835 cal BP (Burley et al. 2015). As the previous studies suggested, soil magnetic and archaeomagnetic studies can indicate that an increase in fire-related activity and an increase in the organic carbon supply from human activities, leading to a transformation into ferrimagnetic minerals (e.g.,Marmet et al. 1999; Hanesch et al. 2006; Fassbinder 2015). Thus, the results from this study also reveal similar magnetic properties that would point to the influence of anthropogenic fire use.

Moreover, AMS $\delta^{13} \mathrm{C}$ values of speleothem can provide supportive evidence for such human activity. Previous studies have suggested that variations in $\delta^{13} \mathrm{C}$ values of speleothems can be largely caused by two effects, both of which are potentially influenced by climate changes (e.g., Fairchild and Baker 2012a; Schwarcz 2013). When the climate is warm/arid, C4 plants with higher $\delta^{13} \mathrm{C}$ values are favored relative to $\mathrm{C} 3$ plants, leading to higher $\delta^{13} \mathrm{C}$ values in speleothems (e.g., Denniston et al. 2007; Zhang et al. 2015). On the other hand, sparse vegetation above caves leads to a lower proportion of organically derived and isotopically lighter $\mathrm{CO}_{2}$ dissolved in the drip water and results in contributing to higher speleothem $\delta^{13} \mathrm{C}$ values (e.g., Baldini et al. 2005; Genty et al. 2006). Carbon and nitrogen stable isotope analyses of bone collagen and apatite (Herrscher et al. 2018; Fenner et al. 2021) and pollen analysis in Tongatapu (Clark et al. 2015) indicated the development of horticulture $\sim 2500 \mathrm{cal}$. BP for the supplement of the lack of marine foods. Therefore, the changes in $\delta^{13} \mathrm{C}$ values of the speleothem can suggest that the shift from dense to sparse vegetation was caused by primitive agriculture. In fact, Manu et al. (2014) reported that $\delta^{13} \mathrm{C}$ of repeatedly cropped soil is heavier than that of the primary forest soil with $>50 \%$ contribution of soil carbon from $\mathrm{C} 4$ grass vegetation in modern Tongatapu.

Future work, such as U/Th dating, is needed to discuss the processes affecting the magnetism of speleothems. The speleothem magnetism is still in the early developmental stages. However, by applying the method proposed in this study to other speleothems, speleothem magnetism can be a new paleoenvironmental proxy in addition to the conventional ones (e.g., oxygen isotope, trace elements/Ca ratio).

\section{Conclusions}

We successfully performed SSM analysis on a speleothem collected from a cave located in Tongatapu Island, the South Pacific, in combination with a series of rock magnetic measurements. We observed magnetic images of the speleothem at the submillimeter scale with SSM and detected the difference in the magnetic field maps associated with the laminated growth structure distinguishing the surface of grayish, black-colored layers and inner white-colored part. The SSM used in this study is capable of detecting magnetic fields with an optimal resolution better than $0.3 \mathrm{~mm}$. Speleothem growth rates are $<100 \mu \mathrm{m} /$ year for temperate regions and can reach $800 \mu \mathrm{m} /$ year in warm and humid climates (e.g., Fairchild and Baker 2012b). Therefore, the scanning resolution of the SSM can be comparable to speleothem annual growth rates. 
Meanwhile, radiocarbon dating results suggest that the existence of a hiatus between the gray layers and the white part may correspond to the boundary between the last glacial and the Holocene. Furthermore, rock magnetic measurements showed that: (1) the magnetic mineral content in the grayish surface layer $\left(2.54 \times 10^{-1} \mathrm{~A} / \mathrm{m}\right)$ is much higher relative to that in the white inner part $\left(6.23 \times 10^{-3} \mathrm{~A} / \mathrm{m}\right)$; (2) the speleothem in this study contains several magnetic minerals (magnetite, maghemite, and hematite or $\varepsilon-\mathrm{Fe}_{2} \mathrm{O}_{3}$ ) with different domain states; (3) hematite or $\varepsilon-\mathrm{Fe}_{2} \mathrm{O}_{3}$ can exist only in the reddish-brown layer and, (4) the contribution of maghemite is much larger in the surface layer than in the inner part. The difference in magnetic mineralogy of the surface layer from that of the inner part suggests the change in the depositional environment of the magnetic minerals supplied to the speleothem to the oxidative condition in the Holocene after the observed hiatus.

\begin{abstract}
Abbreviations
NRM: Natural remanent magnetization; IRM: Isothermal remanent magnetization; TRM: Thermal remanent magnetization; FC: Field cycling; ZFC: Zero field cycling; ThD: Thermal demagnetization; SSM: Scanning SQUID microscope; GSJ: Geological Survey of Japan; AIST: National Advanced Industrial Science and Technology; $B_{h}$ :The mean coercivity of an individual grain population; DP: The dispersion parameter of an individual grain population; SD: Singledomain; PSD: Pseudo-single-domain; MD: Multi-domain.
\end{abstract}

\section{Supplementary Information}

The online version contains supplementary material available at https://doi. org/10.1186/s40623-021-01401-8.

Additional file 1: Figure S1. Left. Location of the Kingdom of Tonga. Right. Location of sampling sites on Tongatapu island.

Additional file 2: Figure S2. We conducted measurements of three components of magnetization with a superconducting rock magnetometer (SRM) in GSJ-Lab, AIST, on the thin section after SSM measurement at each demagnetization step. Figure S2a shows a setup of the experiment, and Fig. S2b shows the photo indicating the size of the thin section (thickness $=0.2 \mathrm{~mm}$ ). Figure $\mathrm{S} 2 \mathrm{c}$ shows the sensor response of the crossSect. $(31 \mathrm{~mm} \times 0.2 \mathrm{~mm}$ ) calculated with a software response (Xuan and Oda, 2019). Nine tensor components of the effective length corresponding to the AAC1 sample $(37 \mathrm{~mm}$ ) were also calculated using the sensor response (shown in Figure S2c). Three components of the magnetization after the correction of the sensor response was calculated from the raw magnetic moment values and the tensor components using the formulae 2 in Xuan and Oda (2019). Deconvolution was not conducted, because the cross-section of the speleothem sample is not uniform along the thin section. Figure S2d shows an estimated magnetization for NRM before demagnetization (top: declination, middle: inclination, bottom: total intensity, and each component). Figure $52 \mathrm{e}-\mathrm{d}$ shows demagnetization diagrams of magnetization picked up from positions at $1 \mathrm{~cm}$ and $3 \mathrm{~cm}$ as representative of upper and lower parts of the sample, respectively. $52 \mathrm{e}$ is the normalized intensity versus AF steps, S2f and S2g are vector endpoint diagrams for positions $1 \mathrm{~cm}$ and $3 \mathrm{~cm}$, respectively. Solid (open) circles correspond to projection onto a horizontal (vertical) plane. It is clear that $80 \%$ of the magnetization of the sample is removed by AF demagnetization up to $30 \mathrm{mT}$. The components removed by AF demagnetization (AFD) at $5 \mathrm{mT}$ indicate that this component is different from the component removed from 5 to $30 \mathrm{mT}$ AFD. The second measurement of NRM with the SSM was used in this study conducted after the measurement with the
SRM, which is different from the other AF step measurements. The sample could have been exposed to the Earth's magnetic field during transportation to the SRM located in another building, which suggests the acquisition of laboratory-induced viscous remanent magnetization after the 1st SSM measurement and before the SRM measurement.

Additional file 3: Figure S3. Scanned images of the separate stalagmite pieces (left) and dating results (right). The red line indicates a growth line, and the white lines indicate the positions of drilling for radiocarbon dating. The light-gray probability density distribution shows each single calibrated age. In contrast, the dark-gray one shows the modeled probability density distribution by the $\mathrm{P}_{-}$Sequence model.

Additional file 4: Table S1. $\delta^{13} \mathrm{C},{ }^{14} \mathrm{C}$ ages, unmodelled calibrated ages and modeled ages for subsamples of the stalagmite.

Additional file 5. Timing of speleothem layers formation.

Additional file 6: Figure S4. (a) Optical image, (b) Optical image overlaid on a magnetic image of NRM after demagnetization at $5 \mathrm{mT}$, (c) Magnetic image of NRM after demagnetization at 5 mT, (d) Optical image, (e) Optical image overlaid on a magnetic image of NRM after demagnetization at 10 $\mathrm{mT}$, (f) Magnetic image of NRM after demagnetization at $10 \mathrm{mT}$, (g) Optical image, (h) Optical image overlaid on a magnetic image of NRM after demagnetization at $30 \mathrm{mT}$, (i) Magnetic image of NRM after demagnetization at $30 \mathrm{mT}$.

Additional file 7: Figure S5. Differentiated FC curves of (a) AAC-B3, (b) AAC-W3, and (c) AAC-M; and differentiated ZFC curves of (d) AAC-B3, (e) AAC-W3 and (f) AAC-M.

\section{Acknowledgements}

We thank Mr. Nivaleti Melekiola (the former Lapaha District Officer) and Mr. Shane Egan (Tonga Maritime Museum) for their assistance in sampling. We also thank Ms. Ayako Katayama for assistance with the sample measurements using the scanning SQUID microscope. A part of this study conducted by NF was carried out as a research assistant in AIST.

\section{Authors' contributions}

NF carried out sample preparations, measurements with SQUID microscope and AGM, data analyses, and drafted the manuscript. $\mathrm{HO}$ and YYo conceived the study, participated in its design and coordination, and helped draft the manuscript. HO maintained the SQUID microscope and developed software for the data analyses. GC organized the fieldwork and collecting the samples. YYa maintained the MPMS and helped with its measurements. All authors read and approved the final manuscript.

\section{Funding}

Part of this research was supported by a Grant from the Japan Society for the Promotion of Science (JSPS) KAKENHI (JP17H01168, JP19H00706, and JP2OH00193) and a Grant-in-Aid for JSPS Fellows DC1 (JP18J21630).

\section{Availability of data and materials}

The datasets used and/or analyzed during the current study are available from the corresponding author upon reasonable request.

\section{Declarations}

Ethics approval and consent to participate

Not applicable.

\section{Consent for publication}

Not applicable.

\section{Competing interests}

The authors declare that they have no competing interests.

\section{Author details}

${ }^{1}$ Atmosphere and Ocean Research Institute, The University of Tokyo, 5-1-5, Kashiwanoha, Kashiwa-shi, Chiba 277-8564, Japan. ${ }^{2}$ Department of Earth and Planetary Science, Graduate School of Science, The University of Tokyo, 
7-3-1 Hongo, Bunkyo-ku, Tokyo 113-0033, Japan. ${ }^{3}$ Institute of Geology and Geoinformation, Geological Survey of Japan, AIST, Central 7,1-1-1 Higashi, Tsukuba 305-8567, Japan. ${ }^{4}$ Archaeology and Natural History, College of Asia and the Pacific, The Australian National University, Canberra, ACT 0200, Australia. ${ }^{5}$ Center for Advanced Marine Core Research, Kochi University, B200 Monobe, Nankoku, Kochi 783-8502, Japan.

Received: 29 April 2020 Accepted: 12 March 2021

Published online: 23 March 2021

\section{References}

Abrajevitch A, Kodama K (2011) Diagenetic sensitivity of paleoenvironmental proxies: a rock magnetic study of Australian continental margin sediments: DIAGENESIS. Geochem Geophys Geosyst. https://doi.org/10.1029/ $2010 \mathrm{gc003481}$

Ahmed IAM, Maher BA (2018) Identification and paleoclimatic significance of magnetite nanoparticles in soils. Proc Natl Acad Sci USA 115:1736-1741. https://doi.org/10.1073/pnas.1719186115

Baldini JUL, McDermott F, Baker A, Baldini LM, Mattey DP, Railsback LB (2005) Biomass effects on stalagmite growth and isotope ratios: a 20th century analogue from Wiltshire, England. Earth Planet Sci Lett 240:486-494. https://doi.org/10.1016/j.epsl.2005.09.022

Burley D, Edinborough K, Weisler M, Zhao J-X (2015) Bayesian modeling and chronological precision for Polynesian settlement of Tonga. PLoS ONE 10:e0120795. https://doi.org/10.1371/journal.pone.0120795

Chen Q, Zhang TW, Wang YT, Zhao JX, Feng YX, Liao W, Wang W, Yang XQ (2019) Magnetism signals in a stalagmite from southern China and reconstruction of paleorainfall during the interglacial-glacial transition. Geophys Res Lett 46:6918-6925. https://doi.org/10.1029/2019gl082204

Childs CW, Wilson AD (1983) Iron oxide minerals in soils of the Ha'apai group, Kingdom of Tonga. Soil Res 21:489-503. https://doi.org/10.1071/sr983 0489

Clark G, Grono E, Ussher E, Reepmeyer C (2015) Early settlement and subsistence on Tongatapu, Kingdom of Tonga: Insights from a 2700-2650calBP midden deposit. J Archaeol Sci Rep 3:513-524. https://doi.org/10.1016/j. jasrep.2015.08.005

Cowie JD, Searle PL, Widdowson JP, Orbell GE (1991) Soils of Tongatapu, King dom of Tonga. DSIR Land Resources, Lower Hutt

de Boer CB, Mullender TAT, Dekkers MJ (2001) Low-temperature behaviour of haematite: susceptibility and magnetization increase on cycling through the Morin transition. Geophys J Int 146:201-216. https://doi.org/10. 1046/j.0956-540x.2001.01443.x

Denniston RF, DuPree M, Dorale JA, Asmerom Y, Polyak VJ, Carpenter SJ (2007) Episodes of late Holocene aridity recorded by stalagmites from Devil's Icebox Cave, central Missouri, USA. Quat Res 68:45-52. https://doi.org/10. 1016/j.yqres.2007.04.001

Denniston RF, Luetscher M (2017) Speleothems as high-resolution paleoflood archives. Quat Sci Rev 170:1-13. https://doi.org/10.1016/j.quascirev.2017. 05.006

Egli R (2004) Characterization of individual rock magnetic components by analysis of remanence curves, 1. Unmixing Natural Sediments. Studia Geophys Geodaetica 48:391-446. https://doi.org/10.1023/B:SGEG.00000 20839.45304.6d

Fairchild IJ, Baker A (2012a) Geochemistry of speleothems. Speleothem Science. Wiley, Chichester, pp 245-289

Fairchild IJ, Baker A (2012b) Introduction to Speleothems and Systems. Speleothem Science. Wiley, Chichester, pp 1-27

Fassbinder JWE (2015) Seeing beneath the farmland, steppe and desert soil: magnetic prospecting and soil magnetism. J Archaeol Sci 56:85-95. https://doi.org/10.1016/j.jas.2015.02.023

Feinberg JM, Lascu I, Lima EA, Weiss BP, Dorale JA, Alexander EC, Edwards RL (2020) Magnetic detection of paleoflood layers in stalagmites and implications for historical land use changes. Earth Planet Sci Lett 530:115946. https://doi.org/10.1016/j.epsl.2019.115946

Fenner JN, Herrscher E, Valentin F, Clark G (2021) An isotopic analysis of Late Lapita and State Period diets in Tonga. Archaeol Anthropol Sci 13:22. https://doi.org/10.1007/s12520-020-01267-z

Font E, Veiga-Pires C, Pozo M, Carvallo C, de Siqueira Neto AC, Camps P, Fabre S, Mirão J (2014) Magnetic fingerprint of southern Portuguese speleothems and implications for paleomagnetism and environmental magnetism: magnetic fingerprint of speleothems. J Geophys Res 119:7993-8020. https://doi.org/10.1002/2014jb011381

Fukuyo N, Clark G, Purcell A, Parton P, Yokoyama Y (2020) Holocene sea level reconstruction using lagoon specific local marine reservoir effect and geophysical modeling in Tongatapu, Kingdom of Tonga. Quat Sci Rev 244:106464. https://doi.org/10.1016/j.quascirev.2020.106464

Genty D, Blamart D, Ghaleb B, Plagnes V, Causse C, Bakalowicz M, Zouari K, Chkir N, Hellstrom J, Wainer K, Bourges F (2006) Timing and dynamics of the last deglaciation from European and North African $813 \mathrm{C}$ stalagmite profiles - comparison with Chinese and South Hemisphere stalagmites. Quat Sci Rev 25:2118-2142. https://doi.org/10.1016/j.quascirev.2006.01. 030

Guyodo Y, LaPara TM, Anschutz AJ, Penn RL, Banerjee SK, Geiss CE, Zanner W (2006) Rock magnetic, chemical and bacterial community analysis of a modern soil from Nebraska. Earth Planet Sci Lett 251:168-178. https://doi. org/10.1016/j.epsl.2006.09.005

Hanesch M, Stanjek H, Petersen N (2006) Thermomagnetic measurements of soil iron minerals: the role of organic carbon. Geophys J Int 165:53-61. https://doi.org/10.1111/j.1365-246X.2006.02933.x

Harrison RJ, Feinberg JM (2008) FORCinel: An improved algorithm for calculating first-order reversal curve distributions using locally weighted regression smoothing: FORCINEL ALGORITHM. Geochem Geophys Geosyst. https://doi.org/10.1029/2008gc001987

He K, Pan Y (2020) Magnetofossil abundance and diversity as paleoenvironmental proxies: a case study from southwest Iberian margin sediments. Geophys Res Lett 47:e2020GL087165. https://doi.org/10.1029/2020g 1087165

Herrscher E, Fenner JN, Valentin F, Clark G, Reepmeyer C, Bouffandeau L, André G (2018) Multi-isotopic analysis of first Polynesian diet (Talasiu, Tongatapu, Kingdom of Tonga). J Archaeol Sci Rep 18:308-317. https://doi.org/ 10.1016/j.jasrep.2018.01.012

Hogg AG, Heaton TJ, Hua Q, Palmer JG, Turney CSM, Southon J, Bayliss A, Blackwell PG, Boswijk G, Ramsey CB, Pearson C, Petchey F, Reimer P, Reimer R, Wacker L (2020) SHCal20 Southern Hemisphere Calibration, 0-55,000 Years cal BP. Radiocarbon 62:759-778. https://doi.org/10.1017/ RDC.2020.59

Jackson MJ, Moskowitz B (2021) On the distribution of Verwey transition temperatures in natural magnetites. Geophys J Int 224:1314-1325. https:// doi.org/10.1093/gji/ggaa516

Jaqueto P, Trindade RIF, Hartmann GA, Novello VF, Cruz FW, Karmann I, Strauss BE, Feinberg JM (2016) Linking speleothem and soil magnetism in the Pau d'Alho cave (central South America): LINKING SPELEOTHEM AND SOIL MAGNETISM. J Geophys Res 121:7024-7039. https://doi.org/10.1002/ 2016jb013541

Kawai J, Oda H, Fujihira J, Miyamoto M, Miyagi I, Sato M (2016) SQUID microscope with hollow-structured cryostat for magnetic field imaging of room temperature samples. IEEE Trans Appl Supercond 26:1-5. https:// doi.org/10.1109/TASC.2016.2536751

Kosterov A, Kovacheva M, Kostadinova-Avramova M, Minaev P, Salnaia N, Surovitskii L, Yanson S, Sergienko E, Kharitonskii P (2020a) High-coercivity magnetic minerals in archaeological baked clay and bricks. Geophys J Int 224:1256-1271. https://doi.org/10.1093/gji/ggaa508

Kosterov A, Sergienko ES, losifidi AG, Kharitonskii PV, Yanson SY (2020b) Analysis of Strong-Field Hysteresis in High Coercivity Magnetic Minerals. Problems of Geocosmos-2018. Springer, Berlin, pp 127-142

Lascu I, Feinberg JM (2011) Speleothem magnetism. Quat Sci Rev 30:33063320. https://doi.org/10.1016/j.quascirev.2011.08.004

Lascu I, Feinberg JM, Dorale JA, Cheng H, Lawrence Edwards R (2016) Age of the Laschamp excursion determined by U-Th dating of a speleothem geomagnetic record from North America. Geology 44:139-142. https:// doi.org/10.1130/G37490.1

Lascu I, Einsle JF, Ball MR, Harrison RJ (2018) The vortex state in geologic materials: a micromagnetic perspective. J Geophys Res 123:7285-7304. https://doi.org/10.1029/2018jb015909

Latham AG, Schwarcz HP, Ford DC (1986) The paleomagnetism and U-Th dating of Mexican stalagmite, DAS2. Earth Planet Sci Lett 79:195-207. https://doi.org/10.1016/0012-821x(86)90053-1

Latham AG, Schwarcz HP, Ford DC (1987) Secular variation of the Earth's magnetic field from 18.5 to $15.0 \mathrm{ka} \mathrm{BP}$, as recorded in a Vancouver Island stalagmite. Can J Earth Sci 24:1235-1241. https://doi.org/10.1139/e87-117 
Latham AG, Schwarcz HP, Ford DC, Pearce GW (1979) Palaeomagnetism of stalagmite deposits. Nature 280:383-385. https://doi.org/10.1038/280383a0

Lima EA, Weiss BP (2016) Ultra-high sensitivity moment magnetometry of geological samples using magnetic microscopy: ULTRA-SENSITIVE MOMENT MAGNETOMETRY. Geochem Geophys Geosyst 17:3754-3774. https://doi. org/10.1002/2016gc006487

Liu Q, Barrón V, Torrent J, Qin H, Yu Y (2010) The magnetism of micro-sized hematite explained. Phys Earth Planet Inter 183:387-397. https://doi.org/ 10.1016/.jpepi.2010.08.008

López-Sánchez J, McIntosh G, Osete ML, del Campo A, Villalaín JJ, Pérez L, Kovacheva M, Rodríguez de la Fuente O (2017) Epsilon iron oxide: origin of the high coercivity stable low Curie temperature magnetic phase found in heated archeological materials: Epsilon archaeomagnetism. Geochem Geophys Geosyst 18:2646-2656. https://doi.org/10.1002/ 2017gc006929

Manu V, Whitbread A, Blair N, Blair G (2014) Carbon status and structural stability of soils from differing land use systems in the Kingdom of Tonga. Soil Use Manage 30:517-523. https://doi.org/10.1111/sum.12135

Marmet E, Bina M, Fedoroff N, Tabbagh A (1999) Relationships between human activity and the magnetic properties of soils: a case study in the medieval site of Roissy-en-France. Archaeol Prospect 6:161-170. https:// doi.org/10.1002/(sici)1099-0763(199909)6:3\%3c161:.aid-arp118\%3e3.0. $\mathrm{Co} ; 2-\mathrm{h}$

Maxbauer DP, Feinberg JM, Fox DL (2016) MAX UnMix: A web application for unmixing magnetic coercivity distributions. Comput Geosci 95:140-145. https://doi.org/10.1016/j.cageo.2016.07.009

Maxbauer DP, Feinberg JM, Fox DL, Nater EA (2017) Response of pedogenic magnetite to changing vegetation in soils developed under uniform climate, topography, and parent material. Sci Rep 7:17575. https://doi. org/10.1038/s41598-017-17722-2

McClean RG, Schofield MA, Kean WF, Sommer CV, Robertson DP, Toth D, Gajdardziska-Josifovska M (2001) Botanical iron minerals: correlation between nanocrystal structure and modes of biological self-assembly. Eur J Mineral 13:1235-1242. https://doi.org/10.1127/0935-1221/2001/ 0013-1235

Morinaga H, Inokuchi H, Yaskawa K (1989) Palaeomagnetism of stalagmites (speleothems) in SW Japan. Geophys J Int 96:519-528. https://doi.org/10. 1111/j.1365-246X.1989.tb06011.x

Myre JM, Lascu I, Lima EA, Feinberg JM, Saar MO, Weiss BP (2019) Using TNT-NN to unlock the fast full spatial inversion of large magnetic microscopy data sets. Earth Planets Space 71:14. https://doi.org/10.1186/ s40623-019-0988-8

Noguchi A, Oda H, Yamamoto Y, Usui A, Sato M, Kawai J (2017) Scanning SQUID microscopy of a ferromanganese crust from the northwestern Pacific: Submillimeter scale magnetostratigraphy as a new tool for age determination and mapping of environmental magnetic parameters: SQUID Microscopy of Ferromanganese Crust. Geophys Res Lett 44:5360-5367. https://doi.org/10.1002/2017gl073201

Oda H, Kawai J, Miyamoto M, Miyagi I, Sato M, Noguchi A, Yamamoto Y, Fujihira J-I, Natsuhara N, Aramaki Y, Masuda T, Xuan C (2016) Scanning SQUID microscope system for geological samples: system integration and initial evaluation. Earth Planets Space 68:179. https://doi.org/10.1186/ s40623-016-0549-3

Oda H, Kawai J, Usui A, Yamamoto Y, Noguchi A, Miyagi I, Miyamoto M, Fujihira J, Sato M (2020) Development of scanning SQUID microscope system and its applications on geological samples: a case study on marine ferromanganese crust. J Phys Conf Ser 1590:012037. https://doi.org/10.1088/ 1742-6596/1590/1/012037

Openshaw S, Latham A, Shaw J (1997) Speleothem palaeosecular variation records from China: their contribution to the coverage of holocene palaeosecular variation data in East Asia. J Geomagn Geoelectr 49:485-505. https://doi.org/10.5636/jgg.49.485

Paterson GA, Zhao X, Jackson M, Heslop D (2018) Measuring, processing, and analyzing hysteresis data. Geochem Geophys Geosyst 19:1925-1945. https://doi.org/10.1029/2018gc007620
Ramsey CB (2009a) Bayesian analysis of radiocarbon dates. Radiocarbon 51:337-360. https://doi.org/10.1017/S0033822200033865

Ramsey CB (2008) Deposition models for chronological records. Quat Sci Rev 27:42-60. https://doi.org/10.1016/j.quascirev.2007.01.019

Ramsey CB (2009b) Dealing with outliers and offsets in radiocarbon dating. Radiocarbon 51:1023-1045. https://doi.org/10.1017/S0033822200034093

Ramsey CB, Lee S (2013) Recent and planned developments of the program OxCal. Radiocarbon 55:720-730. https://doi.org/10.1017/\$003382220 0057878

Roberts AP, Heslop D, Zhao X, Pike CR (2014) Understanding fine magnetic particle systems through use of first-order reversal curve diagrams: FORC diagrams. Rev Geophys 52:557-602. https://doi.org/10.1002/2014rg0004 62

Roy PS (1997) The morphology and surface geology of the islands of Tongatapu and Vava'u, Kingdom of Tonga. In: Alan MS, Russell H, Peter R (eds) Coastal and environmental geoscience studies of the southwest Pacific islands. SOPAC Secretariat, pp 153-173

Schwarcz H (2013) CARBONATE STABLE ISOTOPES | Speleothems. In: Elias SA, Mock CJ (eds) Encyclopedia of Quaternary Science, 2nd edn. Elsevier, Amsterdam, pp 294-303

Spennemann DHR (1997) A Holocene sea-level history for Tongatapu, Kingdom of Tonga. Coastal and environmental geoscience studies of the Southwest Pacific Islands. SOPA Tech Bull 9:115-152

Strauss BE, Strehlau JH, Lascu I, Dorale JA, Penn RL, Feinberg JM (2013) The origin of magnetic remanence in stalagmites: Observations from electron microscopy and rock magnetism: magnetic remanence in stalagmites. Geochem Geophys Geosyst 14:5006-5025. https://doi.org/10.1002/ $2013 g c 004950$

Taylor RM, Schwertmann U (1974) Maghemite in soils and its origin: II. Maghemite syntheses at ambient temperature and pH 7. Clay Miner 10:299-310. https://doi.org/10.1180/claymin.1974.010.4.08

Tuček J, Zbořil R, Namai A, Ohkoshi S-I (2010) E-Fe2O3: An advanced nanomaterial exhibiting giant coercive field, millimeter-wave ferromagnetic resonance, and magnetoelectric coupling. Chem Mater 22:6483-6505. https://doi.org/10.1021/cm101967h

Weiss BP, Lima EA, Fong LE, Baudenbacher FJ (2007) Paleomagnetic analysis using SQUID microscopy. J Geophys Res 112:11715. https://doi.org/10. 1029/2007jb004940

Worthy TH, Wilde K, Williams D (1991) Anahulu Cave, Tongatapu. New Zealand Speleological Bulletin 8:525-528

Yamane M, Yokoyama Y, Hirabayashi S, Miyairi Y, Ohkouchi N, Aze T (2019) Small- to ultra-small-scale radiocarbon measurements using newly installed single-stage AMS at the University of Tokyo. Nucl Instrum Methods Phys Res B 455:238-243. https://doi.org/10.1016/j.nimb.2019.01.035

Yokoyama Y, Miyairi Y, Aze T, Yamane M, Sawada C, Ando Y, de Natris M, Hirabayashi S, Ishiwa T, Sato N, Fukuyo N (2019) A single stage accelerator mass spectrometry at the atmosphere and Ocean Research Institute, The University of Tokyo. Nucl Instrum Methods Phys Res B 455:311-316. https://doi.org/10.1016/j.nimb.2019.01.055

Zhang H, Cai Y, Tan L, Cheng H, Qin S, An Z, Edwards RL, Ma L (2015) Large variations of $\delta 13 \mathrm{C}$ values in stalagmites from southeastern China during historical times: implications for anthropogenic deforestation: $\delta 13 \mathrm{C}$ in stalagmites and anthropogenic deforestation, SE China. Boreas 44:511-525. https://doi.org/10.1111/bor.12112

Zhu Z, Feinberg JM, Xie S, Bourne MD, Huang C, Hu C, Cheng H (2017) Holocene ENSO-related cyclic storms recorded by magnetic minerals in speleothems of central China. Proc Natl Acad Sci USA 114:852-857. https://doi.org/10.1073/pnas.1610930114

\section{Publisher's Note}

Springer Nature remains neutral with regard to jurisdictional claims in published maps and institutional affiliations. 